\title{
Studi Laju Penurunan Frekuensi Pada Sistem Kelistrikan Sumatera Bagian Utara Dengan Skema Pelepasan Beban
}

\author{
Muhammad Rafsanjani'; Retno Aita Diantari ${ }^{2}$ \\ ${ }^{1,2}$ Sekolah Tinggi Teknik PLN \\ ${ }^{1}$ muhammadrafsanjani9@gmail.com \\ ${ }^{2}$ retno.aita@sttpln.ac.id
}

\begin{abstract}
PT PLN (PERSERO) is a company engaged in electricity in Indonesia and plays a role in the generation and distribution of electricity to consumers. PLN has quality standards that must be met, one of which is a stable frequency even though the load keeps changing all the time. In electric power systems, the frequency value is an indicator of the balance between active power generated with a total load of active system power and losses. The frequency value will increase if there is an excess generation and conversely the frequency value will decrease if there is a shortage of generation or overload. If there is a disturbance that causes the large capacity generating unit to be release from the systems (trip), in this case the PLTU Pangkalan Susu and PLTU Nagan Raya will cause a decrease in frequency so that the Northern Sumatera interconnection system is disrupted. A large decrease in frequency can lead to failure of generating units in a row so that it can cause total system failure (blackout). To avoid a total system failure (blackout) a load shedding scheme with under frequency relay (UFR) is carried out. This research is done by experimental methods. According to this research, it's been found that the setting of under frequency relay conducted by PLN UP2B Northern Sumatera is good, in this sense of blocking the system from blackout due to a massive power trip.
\end{abstract}

Keywords: Frequency, Load Shedding, Under Frequency Relay

\begin{abstract}
ABSTRAK
PT PLN (PERSERO) merupakan perusahaan yang bergerak dalam bidang kelistrikan di Indonesia dan berperan dalam pembangkitan serta penyaluran tenaga listrik kepada konsumen. PLN memiliki standar kualitas yang harus terpenuhi, salah satunya adalah frekuensi yang stabil walaupun beban terus berubah sepanjang waktu. Pada sistem tenaga listrik, nilai frekuensi merupakan indikator dari keseimbangan antara daya aktif yang dibangkitkan dengan total beban daya aktif sistem. Nilai frekuensi akan naik apabila terjadi kelebihan pembangkitan dan sebaliknya nilai frekuensi akan turun apabila terjadi kekurangan pembangkitan atau kelebihan beban. Jika terjadi gangguan yang menyebabkan unit pembangkit dengan kapasitas besar terlepas dari sistem (trip), dalam hal ini PLTU Pangkalan Susu dan PLTU Nagan Raya maka akan mengakibatkan penurunan frekuensi sehingga sistem interkoneksi Sumatera bagian Utara terganggu. Penurunan frekuensi yang besar dapat mengakibatkan kegagalan unit-unit pembangkit secara beruntun sehingga dapat menyebabkan kegagalan sistem secara total (blackout). Untuk menghindari terjadinya kegagalan total pada sistem (blackout) maka dilakukan skema pelepasan beban (load shedding) dengan rele frekuensi rendah (UFR). Penelitian ini dilakukan dengan metode eksperimen. Dari hasil penelitian ini, didapat bahwa setting rele UFR yang dilakukan oleh PLN UP2B Sumatera bagian Utara sudah baik, dalam artian dapat menahan sistem dari blackout akibat tripnya pembangkit dengan kapasitas besar.
\end{abstract}

Kata kunci: Frekuensi, Pelepasan Beban, Rele Frekuensi Rendah 


\section{PENDAHULUAN}

Kebutuhan energi listrik terus meningkat seiring dengan pemanfaatannya yang semakin beragam untuk mendukung aktifitas masyarakat dalam kehidupan sehari-hari. Sekarang ini, Listrik sudah menjadi kebutuhan primer bagi sebagian besar masyarakat, sehingga eksistensinya sangat diharapkan cukup tersedia secara kontinyu, mutu, andal, berkualitas, ekonomis, dan ramah lingkungan. Mutu tenaga listrik menyangkut nilai frekuensi, tegangan, dan harmonisa. Bahwasanya besaran-besaran ini harus dijaga dalam batas standar operasinya. Dimana berdasarkan (PERMEN ESDM 37 2008), nilai frekuensi normal adalah $(50 \mathrm{~Hz} \pm 0,2 \mathrm{~Hz}$ ), penyimpangan dalam waktu singkat $(50 \mathrm{~Hz} \pm 0,5 \mathrm{~Hz})$ selama kondisi gangguan masih diperbolehkan bekerja pada $47,5 \mathrm{~Hz}$ dan $52,0 \mathrm{~Hz}$. Jika terjadi penyimpangan nilai frekuensi maka diatur secara otomatis oleh governor yang ada pada pembangkit dan secara manual oleh operator.

Nilai frekuensi standar untuk sistem tenaga listrik milik PLN adalah $50 \mathrm{~Hz}$ (PERMEN ESDM 37 2008), namun dalam operasinya tidak selalu stabil $(50 \mathrm{~Hz})$ bisa naik atau turun. Frekuensi pada sistem tenaga listrik akan stabil jika daya aktif yang dibangkitkan harus sama dengan total daya aktif beban dan rugi-rugi pada sistem tenaga listrik. Apabila daya aktif yang dibangkitkan lebih besar daripada total daya aktif beban dan rugi-rugi pada sistem tenaga listrik, maka frekuensi akan naik, hal ini dapat disebabkan karena hilangnya beban secara tiba-tiba, contohnya apabila terjadi gangguan pada suatu gardu induk dengan beban yang besar. Sedangkan apabila daya aktif yang dibangkitkan lebih kecil daripada total daya aktif beban dan rugi-rugi pada sistem tenaga listrik, maka frekuensi akan turun, hal ini dapat disebabkan karena gangguan pada pembangkit yang menyebabkan pembangkit tersebut terlepas dari sistem.

Menurut penelitian sebelumnya pada jurnal penelitian Noviyani, Erni. 2016. Dengan judul "Studi Pelepasan Beban pada Skema Pertahanan (Defence Scheme) Jaringan Sistem Khatulistiwa" yang terbit dari jurnal teknik elektro Universitas Tanjungpura Vol 2 No 1, 2016. Dalam penelitian ini membahas skema pertahanan (Defence Scheme) adalah suatu tindakan dalam mempertahankan sistem dari hal - hal yang tidak diinginkan seperti pemadaman partial / sebagian dan pemadaman total (black out). Skema pertahanan diperlukan agar sistem kelistrikan tidak mengalami keruntuhan sistem (collapsed). Tindakan- tindakan yang dilakukan dalam cakupan skema pertahanan / defence scheme adalah Brown Out, Manual Load Shedding (MLS), Load Shedding (Under Frekuensi Relay), Island Operation dan host load.

Kemudian penelitian Hadi, Abdul. 2016. Dengan judul "Studi Pelepasan Beban Dengan Menggunakan Relai Frekuensi Kurang Pada sistem Tenaga Listrik" yang terbit dari jurnal Jom FTEKNIK Vol 3 No 2 Oktober 2016. Dalam penelitian ini membahas tentang untuk mengimbangi turunnya frekuensi yang dapat membuat terjadinya kerusakan pada sistem, sebagian beban harus dilepaskan supaya frekuensi dari sistem tidak turun jauh dari batas yang di ijinkan dan segera kembali dalam rentang waktu yang masih di perbolehkan.

Dan penelitian Nugraheni, Ari. 2011. Dengan judul "Simulasi Pelepasan Beban Dengan Menggunakan Rele Frekuensi Pada sistem Tenaga Listrik CNOOS SES LTD". Depok: Universitas Indonesia. Dalam penelitian ini membahas Pelepasan beban merupakan fenomena sistem tenaga listrik yang mengizinkan beberapa beban lepas dalam rangka memelihara kestabilan sistem tenaga listrik. Pelepasan beban dapat terjadi akibat penurunan frekuensi karena adanya ketidakseimbangan antara daya aktif yang dibangkitkan generator dan konsumsi beban. 
Tujuan dilakukan penelitian ini untuk mengkaji skema pertahanan sistem kelistrikan sumbagut ketika terjadi gangguan trip pembangkit besar PLTU Pangkalan Susu dan PLTU Nagan Raya.

\section{METODE/PERANCANGAN PENELITIAN}

\subsection{Menentukan Konstanta Inersia Sistem}

Konstanta inersia sistem memegang peranan penting dalam penentuan perubahan kecepatan penurunan frekuensi. Semakin besar harga konstanta inersia semakin baik karakteristik frekuensi sistem, yakni besar kecepatan penurunan frekuensi sistem akan lebih kecil. Berikut adalah rumus untuk mencari kostanta inersia sistem :

$$
H_{\text {sistem }}=\frac{\text { Energi }(M W s)}{\text { Kapasitas }(M V A)}
$$

\subsection{Menghitung Faktor Kelebihan Beban}

Sebuah sistem akan mengalami kelebihan beban segera setelah terjadi kehilangan sebagian daya pembangkitan atau dapat juga disebabkan oleh pertambahan beban yang besar secara tiba-tiba. Untuk dapat membandingkan tingkat ketidakseimbangan antara daya pembangkitan dengan daya beban pada suatu sistem, telah didefinisikan suatu faktor kelebihan beban ( Over Load / OL ).

$$
\begin{gathered}
\text { Kelebihan Beban }(O L)=\frac{\text { daya pembangkitan yang hilang }}{\text { sisa daya pembangkitan }} \\
O L=\frac{P_{G o}-\left(P_{G o}-\Delta P_{G}\right)}{\left(P_{G o}-\Delta P_{G}\right)} \times 100 \% .
\end{gathered}
$$

\subsection{Menghitung Frekuensi Akhir Sistem}

Dengan mengetahui besarnya kelebihan beban pada sebuah sistem yang diakibatkan oleh gangguan unit pembangkit maka dapat diketahui frekuensi akhir pada sebuah sistem ketika terjadi gangguan unit pembangkit tersebut dengan cara menghitung:

$$
f=f_{0}\left[\frac{1+\frac{d-1}{d} O L}{1+O L}\right]
$$

\subsection{Menghitung Laju Penurunan Frekuensi}

Pada saat sistem mengalami gangguan dan menyebabkan tripnya suatu pembangkit dengan kapasitas yang cukup besar yang membangkitkan daya sebesar $\Delta p_{G}$ sehingga sistem mengalami kekurangan daya, yang mengakibatkan turunnya frekuensi. Adapun cara untuk mengetahui laju penurunan frekuensi yaitu dengan mengitung besarnya daya beban pada frekuensi turun menyentuh rele UFR tahap 1 yaitu $49,3 \mathrm{~Hz}$ adalah :

$$
P_{L 1} \quad=P_{L 0}\left(1-d \frac{f_{0}-f_{1}}{f_{0}}\right)
$$


Besarnya kecepatan penurunan frekuensi adalah :

$$
\frac{d f_{1}}{d t_{1}}=\frac{f_{1}}{2 H} \frac{\left(P_{G 0}-\Delta P_{G}\right)-\left(P_{L 1}-L_{1}\right)}{P_{G 0 T}-P_{S 0 T}}
$$

Frekuensi saat beban dilepas pada setiap tahap adalah :

$$
F_{1} \quad=f_{1}+\frac{d f_{1}}{d t_{1}} \cdot t
$$

Besarnya waktu pada saat dilakukannya pelepasan beban tahap 1 sebagai berikut :

$$
t_{1} \quad=\left|\frac{f_{1}-f_{0}}{\left(\frac{d f_{1}}{d t_{1}}\right)}\right|
$$

\subsection{Perancangan Penelitian}

Mulai

Beban output seluruh unit pembangkit $(\mathrm{MW})=P_{G O T}$

Daya output pembangkit $(\mathrm{MW})=P_{G 0}$

Daya beban sistem $(\mathrm{MW})=P_{L 0}$

Beban output unit pembangkit yang trip $(\mathrm{MW})=P_{S O T}$

Daya yang dibangkitkan unit yang mengalami gangguan $(\mathrm{MW})=\Delta P_{G}$

Konstanta Inersia Sistem $(M W s / M V A)=\mathrm{H}$

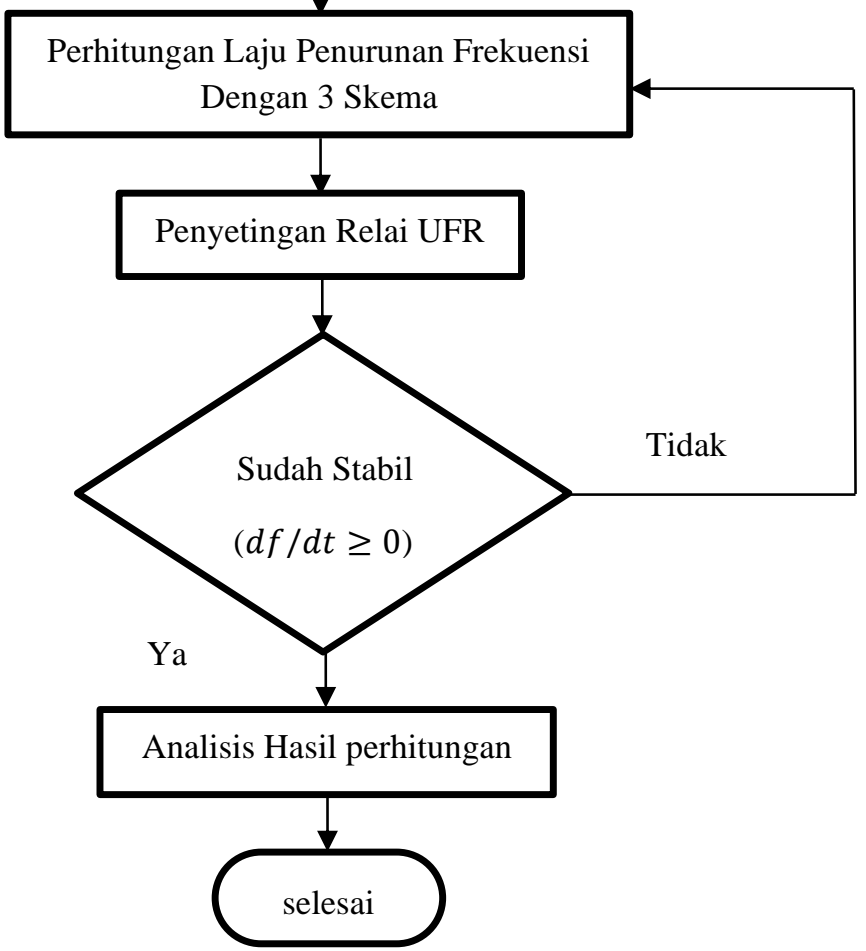

Gambar 1. Diagram Alir Perancangan Penelitian 


\section{HASIL DAN PEMBAHASAN}

Menurut standar PLN, nilai frekuensi sistem tenaga listrik adalah $50 \mathrm{~Hz}$, berlaku untuk seluruh Indonesia. Sistem interkoneksi Sumbagut pada tahun 2019 memiliki daya terpasang sekitar 2928,96 MW dengan daya mampu 2600,56 MW. Strategi yang diterapkan untuk menjaga frekuensi pada batas nominal pada sistem Sumatera bagian Utara sebagai berikut :

Tabel 1. Skema Pertahanan Sistem Sumatera Bagian Utara

\begin{tabular}{|l|l|l|}
\hline Over frekuensi & $52,0 \mathrm{~Hz}$ & \\
\hline Batas ekskursi atas & $50,5 \mathrm{~Hz}$ & \\
\hline Batas atas frekuensi & $50,2 \mathrm{~Hz}$ & \\
\hline Frekuensi nominal & $50,0 \mathrm{~Hz}$ & \\
\hline Batas bawah frekuensi & $49,8 \mathrm{~Hz}$ & \\
\hline Batas ekskursi bawah & $49,5 \mathrm{~Hz}$ & \\
\hline UFR Tahap 1 & $49,3 \mathrm{~Hz}$ & Melepas Beban 101 MW \\
\hline UFR Tahap 2 & $49,1 \mathrm{~Hz}$ & Melepas Beban 122 MW \\
\hline UFR Tahap 3 & $48,9 \mathrm{~Hz}$ & Melepas Beban 138 MW \\
\hline UFR Tahap 4 & $48,8 \mathrm{~Hz}$ & Melepas Beban 136 MW \\
\hline UFR Tahap 5 & $48,7 \mathrm{~Hz}$ & Melepas Beban 135 MW \\
\hline Island Tahap 1 & $48,5 \mathrm{~Hz}$ & 1.Nagan raya; 2.Arun+Sumut \\
\hline Island Tahap 2 & $48,4 \mathrm{~Hz}$ & 1.Nagan raya; 2.Arun; 3.Sumut \\
\hline Island Tahap 3 & $48,3 \mathrm{~Hz}$ & 1.Nagan raya; 2.Arun; 3.Medan; 4.Tapanuli \\
\hline Island Tahap 4 & $48,1 \mathrm{~Hz}$ & 1.Nagan raya; 2.Arun; 3.Medan; 4.Tapanuli \\
\hline Host Load & $47,5 \mathrm{~Hz}$ & Operasi House Load Pembangkit \\
\hline
\end{tabular}

\subsection{Perhitungan penurunan Frekuensi Akibat Trip PLTU Pangkalan Susu dan PLTU Nagan Raya}

Pada pembahasan ini akan dilakukan simulasi trip dengan 3 skema pada unit pembangkit PLTU Pangkalan Susu dan PLTU Nagan Raya, dimana untuk skema 1 yaitu trip unit 1 PLTU Pangkalan Susu, Skema 2 yaitu trip unit 1 dan 2 PLTU Pangkalan Susu dan Skema 3 yaitu trip Unit 1 dan 2 PLTU Pangkalan Susu serta trip unit 1 dan 2 PLTU Nagan Raya. Dari hasil perhitungan semua skema akan didapatkan hasil pada setiap skema 1,2 dan 3, tahapan kerja Rele UFR dan besarnya beban yang dilepas pada setiap tahap seperti pada table berikut:

Tabel 2. Hasil Perhitungan 3 Skema Trip Pembangkit

\begin{tabular}{|c|c|c|c|c|c|c|c|c|}
\hline Skema & $\begin{array}{c}\text { Daya } \\
\text { yang } \\
\text { hilang } \\
(\mathrm{MW})\end{array}$ & $\begin{array}{c}\text { Faktor } \\
\text { kelebihan } \\
\text { beban } \\
(\%)\end{array}$ & $\begin{array}{c}\text { Frekuensi } \\
\text { Akhir } \\
\text { Sistem } \\
(\mathrm{Hz})\end{array}$ & $\begin{array}{c}\text { Tahapan } \\
\text { Pelepasa } \\
n\end{array}$ & $\begin{array}{l}\text { Setting } \\
\text { Rele } \\
\text { Frekuensi } \\
(\mathrm{Hz})\end{array}$ & $\begin{array}{l}\text { Beban } \\
\text { yang } \\
\text { dilepas } \\
\text { (MW) }\end{array}$ & $\begin{array}{l}\text { Setting } \\
\text { Frekuensi } \\
(\mathrm{Hz})\end{array}$ & $\begin{array}{l}\text { Waktu } \\
\text { (detik) }\end{array}$ \\
\hline \multirow{2}{*}{1} & \multirow{2}{*}{220} & \multirow{2}{*}{8,33} & \multirow{2}{*}{48,07} & 1 & 49,3 & 101 & 49,29 & 9,861 \\
\hline & & & & 2 & 49,1 & 122 & 49,13 & 10,361 \\
\hline \multirow{3}{*}{2} & \multirow{3}{*}{440} & \multirow{3}{*}{18,17} & \multirow{3}{*}{46,15} & 1 & 49,3 & 101 & 49,23 & 1,136 \\
\hline & & & & 2 & 49,1 & 122 & 49,07 & 1,780 \\
\hline & & & & 3 & 48,9 & 138 & 48,92 & 2,449 \\
\hline 3 & 660 & 24,99 & 45,00 & 1 & 49,3 & 101 & 49,18 & 0,720 \\
\hline
\end{tabular}


JURNAL ILMIAH SUTET

Vol. 9, No. 2, Desember 2019, P-ISSN 2356-1505, E-ISSN 2656-9175 https://doi.org/10.33322/sutet.v9i2.584

\begin{tabular}{|c|c|c|c|c|c|c|c|c|}
\hline \multirow{3}{*}{ Skema } & $\begin{array}{c}\text { Daya } \\
\text { yang } \\
\text { hilang } \\
(\mathrm{MW})\end{array}$ & $\begin{array}{c}\text { Faktor } \\
\text { kelebihan } \\
\text { beban } \\
(\%)\end{array}$ & $\begin{array}{c}\text { Frekuensi } \\
\text { Akhir } \\
\text { Sistem } \\
(\mathrm{Hz})\end{array}$ & $\begin{array}{c}\text { Tahapan } \\
\text { Pelepasa } \\
\mathrm{n}\end{array}$ & $\begin{array}{c}\text { Setting } \\
\text { Rele } \\
\text { Frekuensi } \\
(\mathrm{Hz})\end{array}$ & $\begin{array}{c}\text { Beban } \\
\text { yang } \\
\text { dilepas } \\
(\mathrm{MW})\end{array}$ & $\begin{array}{c}\text { Setting } \\
\text { Frekuensi } \\
(\mathrm{Hz})\end{array}$ & $\begin{array}{c}\text { Waktu } \\
\text { (detik) }\end{array}$ \\
\cline { 5 - 10 } & & & & 2 & 49,1 & 122 & 49,03 & 0,945 \\
\cline { 5 - 10 } & & & 3 & 48,9 & 138 & 48,88 & 1,797 \\
\cline { 5 - 9 } & & & & 4 & 48,8 & 136 & 48,83 & 2,130 \\
\hline
\end{tabular}

Tabel 3. Laju Penurunan Frekuensi

\begin{tabular}{|c|c|c|c|c|c|}
\hline \multirow{2}{*}{ Skema } & Unit Pembangkit Trip & \multicolumn{4}{|c|}{ Laju Penurunan Frekuensi (Hz/detik) } \\
\cline { 3 - 6 } & Uahap 1 & Tahap 2 & Tahap 3 & Tahap 4 \\
\hline 1 & Unit 1 PLTU Pangkalan Susu & $-0,0720$ & 0,3194 & ${ }^{* \star * \star *}$ & ${ }^{\star \star \star \star \star}$ \\
\hline 2 & Unit 1 dan 2 PLTU Pangakalan Susu & $-0,6773$ & $-0,2481$ & 0,2242 & ${ }^{* * \star \star *}$ \\
\hline 3 & $\begin{array}{c}\text { Semua Unit PLTU Pangkalan Susu dan } \\
\text { PLTU Nagan Raya }\end{array}$ & $-1,1376$ & $-0,6657$ & $-0,1450$ & 0,3310 \\
\hline
\end{tabular}

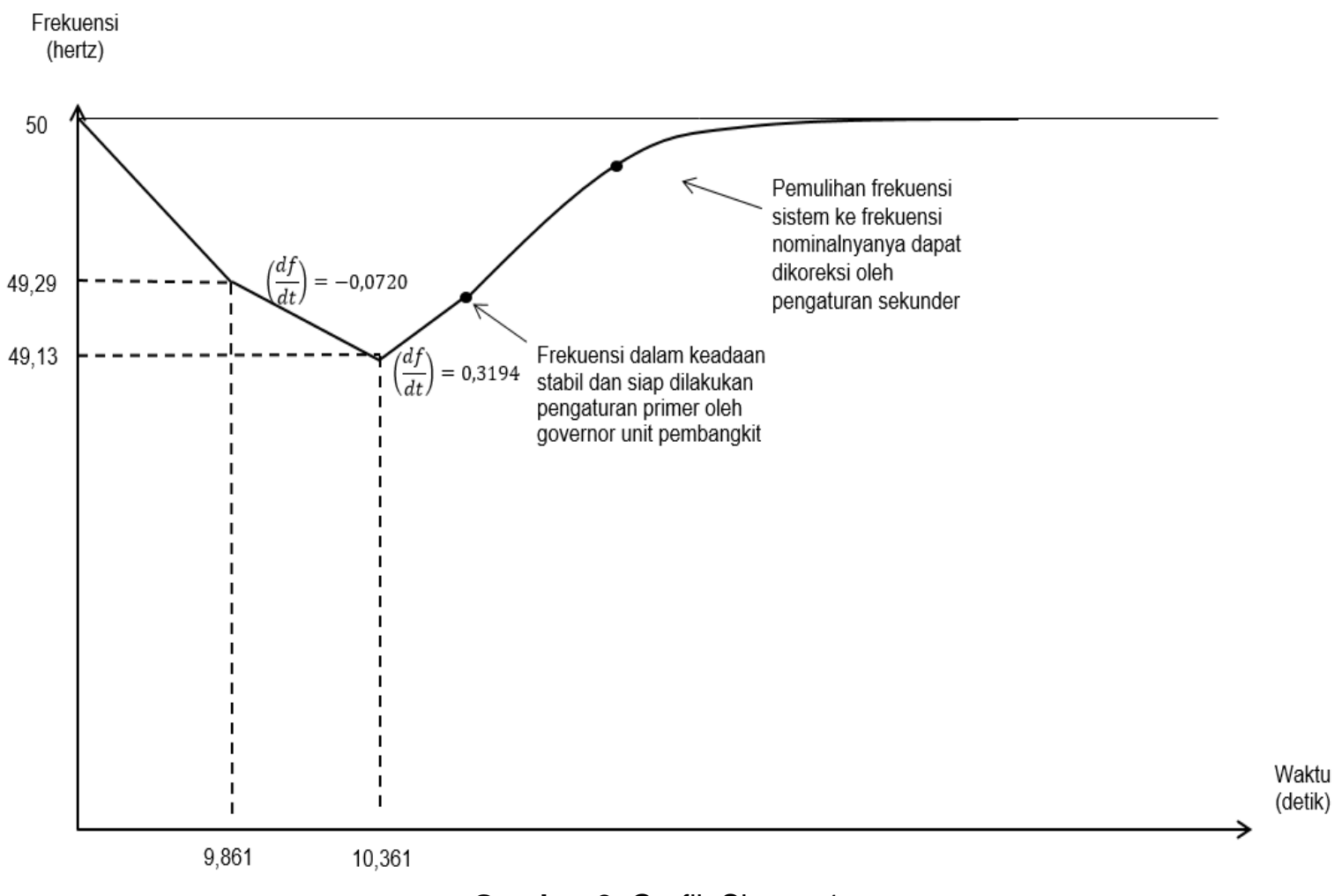

Gambar 2. Grafik Skema 1 
Vol. 9, No. 2, Desember 2019, P-ISSN 2356-1505, E-ISSN 2656-9175

https://doi.org/10.33322/sutet.v9i2.584

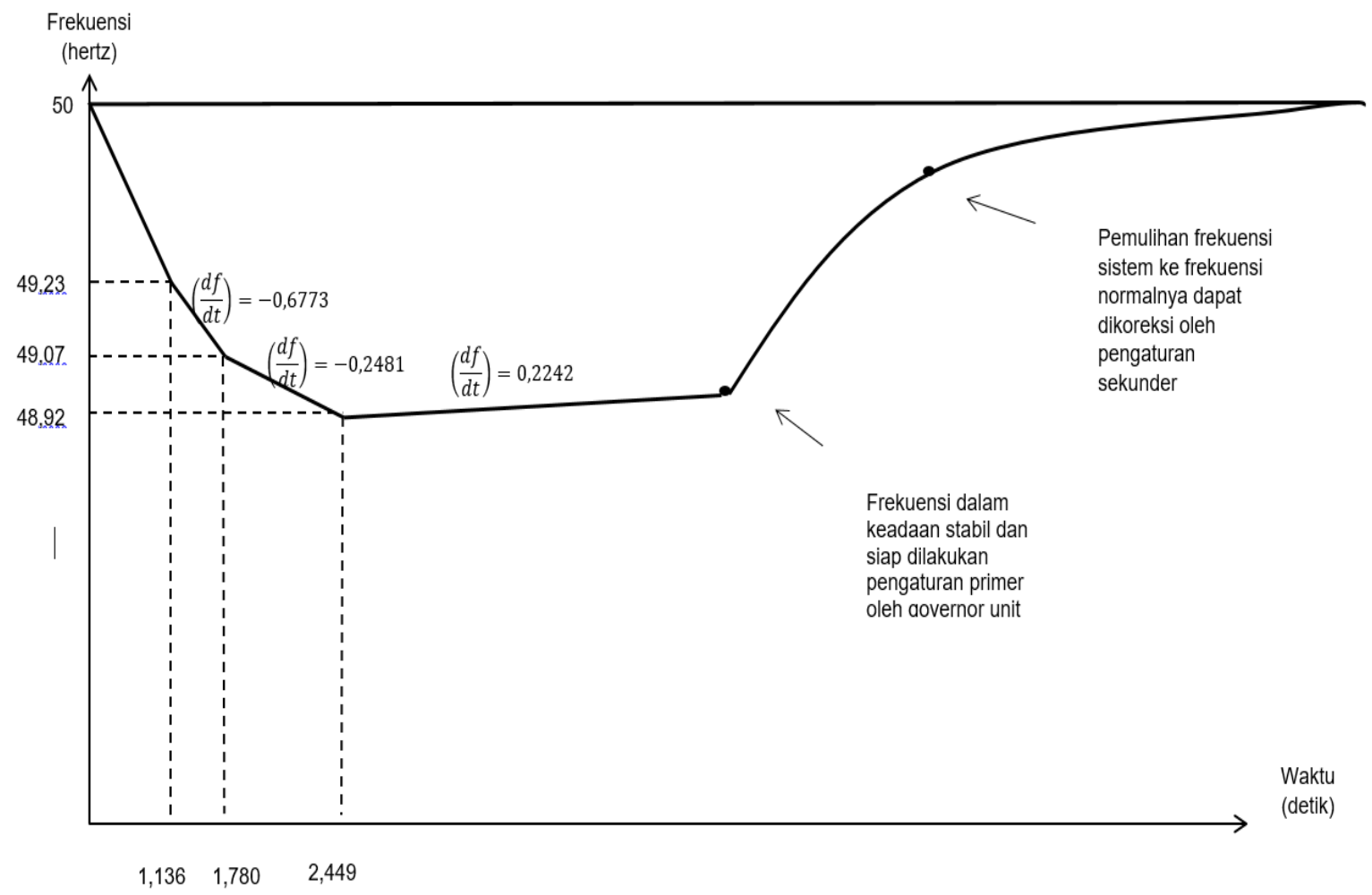

Gambar 3. Grafik Skema 2

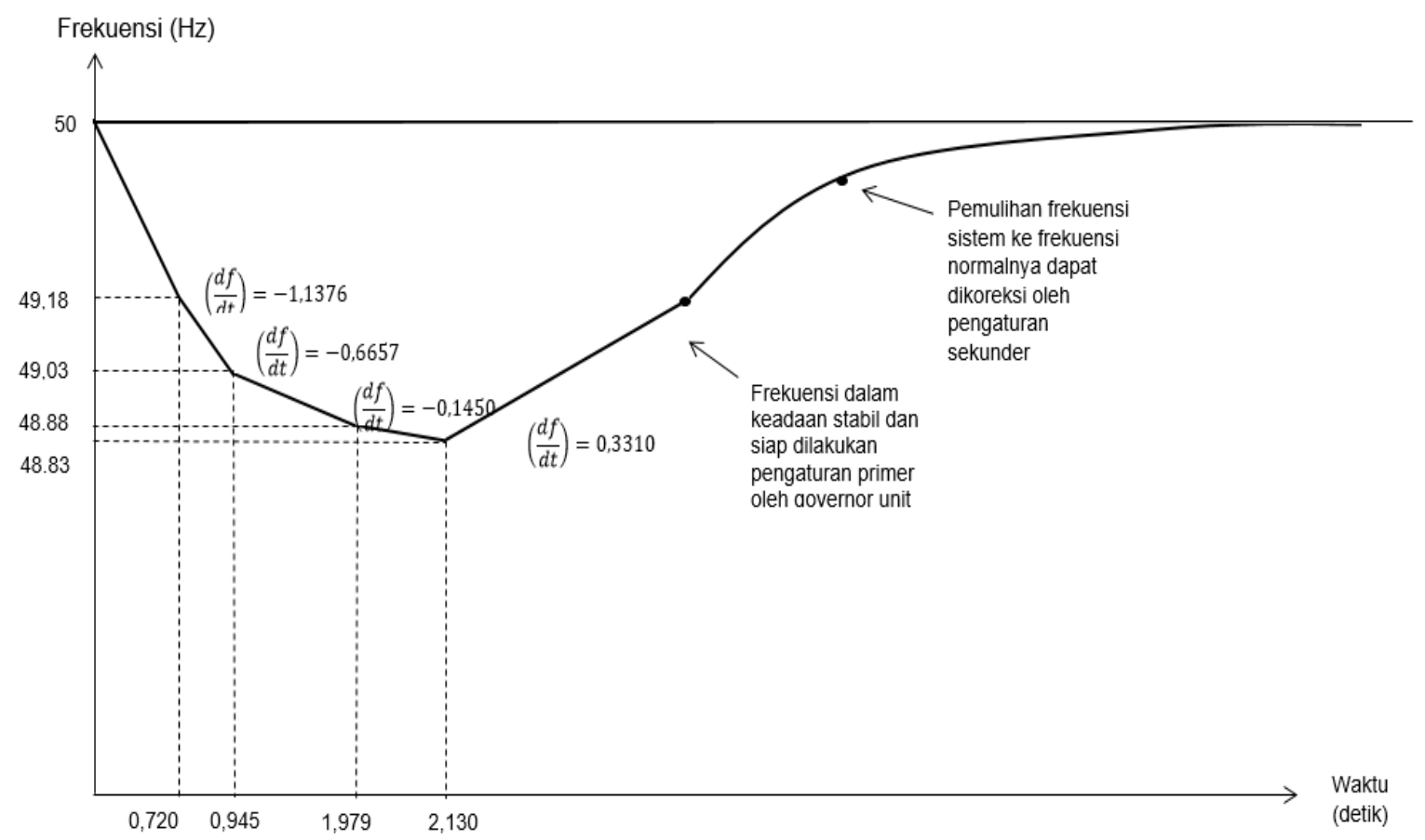

Gambar 4. Grafik Skema 3 
3.2. Analisis Perhitungan penurunan Frekuensi Akibat Trip PLTU Pangkalan Susu dan PLTU Nagan Raya

1. Pada perhitungan trip PLTU Pangkalan Susu unit 1 dengan daya terpasang 220 MW dan faktor kelebihan beban sebesar $8,33 \%$, menyebabkan penurunan frekuensi pada sistem hingga $49,13 \mathrm{~Hz}$, relai UFR bekerja sampai tahap 2 dengan melepas beban sebesar $223 \mathrm{MW}$ sudah dapat menaikkan kembali frekuensi dalam artian $\left(\frac{d f}{d t}\right) \geq 0$. Sehingga untuk mengembalikan frekuensi ke nilai nominal dilanjutkan dengan pengaturan primer oleh governor dan pengaturan sekunder oleh dispatcher.

2. Selanjutnya simulasi gangguan PLTU Pangkalan Susu unit 1 dan 2 dengan total daya terpasang keduanya sebesar $440 \mathrm{MW}$ dan faktor kelebihan beban 18,17\%, menyebabkan frekuensi turun sangat drastis hingga menyentuh $48,9 \mathrm{~Hz}$, relai UFR bekerja sampai tahap 3 dengan melepas beban sebanyak $361 \mathrm{MW}$ sehingga frekuensi dapat naik kembali ke nilai nominal dilanjutkan dengan pengaturan primer oleh governor dan pengaturan sekunder oleh dispatcher.

3. Pada Simulasi Gangguan PLTU Pangkalan Susu Unit 1 dan 2 juga PLTU Nagan Raya unit 1 dan 2 dengan total daya terpasang kedua pembangkit tersebut adalah $660 \mathrm{MW}$ dengan faktor kelebihan beban sebesar 24,99\%, menyebabkan sistem tidak stabil Karena frekuensi turun sangat rendah dengan kecuraman penurunan frekuensi $\left(\frac{d f}{d t}\right)$ sebesar -1,1376 Hz/detik; -0,6657 Hz/detik; dan -0,1450 Hz/detik ; $0,3310 \mathrm{~Hz} /$ detik. Pada simulasi ini frekuensi turun hingga $48,83 \mathrm{~Hz}$, UFR bekerja hingga tahap 4 dengan melepas beban sebanyak $497 \mathrm{MW}$, frekuensi sudah dalam keadaan stabil dalam artian $\left(\frac{d f}{d t}\right) \geq 0$ yang selanjutnya dilakukan pengaturan primer oleh governor dan pengaturan sekunder oleh dispatcher untuk mengembalikan frekuensi ke nilai nominal yaitu $50 \mathrm{~Hz}$.

\section{KESIMPULAN}

1. Perhitungan skema trip unit 1 PLTU Pangkalan Susu dengan faktor kelebihan beban $8,33 \%$, menyebabkan frekuensi turun. Pada skema pertama, relai UFR bekerja hingga tahap ke 2 dengan laju penurunan frekuensi tahap 1 sebesar $\left(\frac{d f}{d t}\right)=-0,0720 \mathrm{~Hz} /$ detik, sehingga frekuensi turun hingga $49,13 \mathrm{~Hz}$, dengan melepas beban sebanyak $223 \mathrm{MW}$ pada tahap 1 dan 2 nilai frekuensi dapat naik kembali ke nilai nominal $50 \mathrm{~Hz}$.

2. Perhitungan skema trip pada unit 1 dan 2 PLTU Pangkalan Susu dengan faktor kelebihan beban $18,17 \%$ menyebabkan frekuensi turun. Pada skema kedua, relai UFR bekerja hingga tahap 3 dengan laju penurunan frekuensi tahap 1 sebesar $\left(\frac{d f}{d t}\right)=-0,6673 \mathrm{~Hz} /$ detik, dan tahap 2 sebesar $\left(\frac{d f}{d t}\right)=-0,2481 \mathrm{~Hz} /$ detik, sehingga frekuensi turun hingga $48,92 \mathrm{~Hz}$, dengan melepas beban sebanyak $361 \mathrm{MW}$ pada tahap 1,2 dan 3, nilai frekuensi dapat naik kembali ke nilai nominal $50 \mathrm{~Hz}$.

3. Perhitungan skema trip unit 1,2 PLTU Pangkalan Susu dan unit 1,2 PLTU Nagan Raya dengan faktor kelebihan beban sebesar $24,99 \%$ menyebabkan frekuensi turun drastis, Pada skema ketiga, relai UFR bekerja hingga tahap 4 dengan laju 
penurunan frekuensi tahap 1 sebesar $\left(\frac{d f}{d t}\right)=-1,1376 \mathrm{~Hz} /$ detik, tahap 2 sebesar $\left(\frac{d f}{d t}\right)=-0,6651 \mathrm{~Hz} /$ detik dan tahap 3 sebesar $\left(\frac{d f}{d t}\right)=-0,1450 \mathrm{~Hz} /$ detik, sehingga frekuensi turun hingga 48,83 Hz. Dengan melepas beban sebanyak $497 \mathrm{MW}$ dari tahap 1,2,3 dan 4, nilai frekuensi tidak dapat naik kembali ke nilai nominal frekuensi $50 \mathrm{~Hz}$.

4. Pada perhitungan semua skema trip pembangkit, sistem kelistrikan Sumatera bagia Utara hanya mampu kehilangan daya sebesar $660 \mathrm{MW}$, hal ini dikarenakan cadangan yang tersedia pada sistem hanya mampu menanggulangi kekurangan daya maksimal 660, jika terjadi trip pembangkit lebih besar daripada skema trip terbesar maka sistem kelistrikan Sumatera bagian Utara padam total (black out).

\section{DAFTAR PUSTAKA}

[1] Marsudi, Djiteng. 2006. Operasi Sistem Tenaga Listrik. Yogyakarta. Graha IImu.

[2] Marsudi Djiteng. 2011. Pembangkitan Energi Listrik. Jakarta. Erlangga.

[3] PT. PLN (persero) UP2B. 2019. Data Operasi Sistem Sumbagut. Sumatera Utara.

[4] Kundur, Prabha. 1994. Power System Stability and Control. Toronto. McGraw-Hill.

[5] Noviyani, Erni. 2016. Studi Pelepasan Beban Pada Skema Pertahanan (Defence Scheme) Sistem Jaringan Khatulistiwa. Pontianak. Universitas Tanjung Pura.

[6] Hadi, Abdul. 2016. Studi Pelepasan Beban Dengan Menggunakan Relai Frekuensi Kurang Pada sistem Tenaga Listrik. Pekanbaru. Universitas Riau.

[7] Nugraheni, Ari. 2011. Simulasi Pelepasan Beban Dengan Menggunakan Rele Frekuensi Pada sistem Tenaga Listrik CNOOS SES LTD. Depok. Universitas Indonesia 